\title{
Quociente de Inteligência e Aquisição de Leitura: Um Estudo Correlacional
}

\author{
Ana Cláudia Bortolozzi Maia ${ }^{12}$ \\ Universidade Estadual de São Paulo, Bauru \\ Mônica Lúcia Fonseca \\ Universidade Federal de São Carlos
}

\begin{abstract}
Resumo
O estudo foi desenvolvido para investigar a relação entre QI, medido pelo teste de inteligência WISC, e a aquisição de leitura de palavras simples. Cinqüenta e seis alunos, de ambos os sexos, de 7 a 15 anos, do Ciclo Básico de alfabetização de uma escola pública, foram avaliados em leitura e no WISC, no início e no final do ano letivo. Os alunos, em geral, apresentaram níveis aumentados de QI e de aquisição de leitura na segunda avaliação, entretanto, sem correlação entre essas variáveis; o QI mostrouse ineficiente para prever sucesso ou fracasso na aquisição de leitura. Os dados sugerem a necessidade de mais investigações sobre o uso de testes de inteligência na avaliação psicológica, no contexto educacional.

Palavras-chave: Inteligência; WISC; leitura; avaliação psicológica.
\end{abstract}

Intelligence Quotient and Reading Acquisition: A Correlational Study

\begin{abstract}
The study was developed to investigate the relation between IQ testing, evaluated by the WISC, and the reading acquisition of simple words. Fifty six students, of both sexes, between 7 and 15 years old, studying in the elementary classes of a public school, were evaluated on reading and WISC performance at the beginning and at the end of the school year. The students, in general, showed increased levels of IQ and reading acquisition on the second evaluation. However, there was no correlation between these variables. The IQ testing was ineffective in predicting success or failure in reading acquisition. The data suggest the need for more investigations on the use of intelligence testing in psychological evaluation in the educational environment. Keywords: Intelligence; WISC; reading; psychological evaluation.
\end{abstract}

Muitos alunos que apresentam dificuldades na aprendizagem, sejam essas interpretadas como problemas de comportamento, inabilidade motora ou déficit intelectual, são considerados no sistema educacional como Deficientes Mentais: Educáveis ou Limítrofes (Almeida, 1992; Machado, 1996; Patto, 1992). O diagnóstico formal de deficiência mental é resultado de uma avaliação psicológica cujas conseqüências, no âmbito educacional, são complexas e ambíguas. Há, na literatura, várias reflexões críticas quanto aos instrumentos e às finalidades da avaliação psicológica, especialmente quando são utilizados exclusivamente testes psicológicos, e entre eles os de inteligência, em detrimento de avaliações dos fatores pedagógicos e sociais mais amplos

\footnotetext{
${ }^{1}$ Endereço para correspondência: Ana Cláudia Bortolozzi Maia, Rua Mário Fundagem Nogueira, no 1-43, 17017-100, Bauru, SP. Fones: (14) 2349608 / 2216087, Fax: (14) 2342917. E-mail: aclaudia@fc.unesp.br

${ }^{2}$ Esse artigo é parte integrante das dissertações de mestrado das autoras, sob orientação de Deisy de Souza a quem agradecem pela dedicação e fundamental contribuição. Também agradecem a Bartolomeu Tróccoli (UNB/Brasilia/DF) pela análise estatística dos dados; Júlio C. de Rose; Ana Lúcia Rossito; Nivaldo Nale e Olga Maria P. R. Rodrigues pelas excelentes sugestões e, ainda, a Maria Goreti da Fonseca e aos alunos do Curso de Graduação em Psicologia da UFSCar/SP que contribuíram para a coleta de dados. A pesquisa contou com apoio da CAPES (bolsas de mestrado) e do CNPq (Processo \#522290/95-7).
}

(Almeida, 1992; Carvalho, 1993; Fonseca, 1987; Kassar, 1995; Machado, 1996; Maia, 1997; Patto, 1992; Salazar, 1997). A contribuição que se pretende apresentar a este debate consiste na investigação da relação entre o desempenho em testes de inteligência e a aprendizagem acadêmica de alunos que estão em processo de alfabetização.

O primeiro teste de inteligência foi criado por Alfred Binet, então diretor do laboratório de psicologia da Sorbonne, por solicitação do Ministério da Educação da França. Ele elaborou um instrumento que consistia de um conjunto de tarefas breves, relacionadas aos problemas da vida quotidiana, que, supostamente, implicavam certos procedimentos racionais básicos, para identificar crianças que necessitariam de educação diferenciada (Carraher, 1989; Gould, 1991). Binet, no entanto, defendia que a inteligência era por demais complexa para ser expressa por um único número (QI) e negou-se não apenas a qualificar o QI como inteligência inata, como também a considerá-lo um recurso geral para a hierarquização de alunos, segundo seu valor intelectual, chegando mesmo a prever a possibilidade do mau uso de suas escalas de inteligência. Essa profecia se concretizou após a sua morte, em 1911, quando suas instruções foram distorcidas pelos hereditaristas americanos, que logo transformaram sua escala em um formulário 
aplicado de forma rotineira a todas as crianças, para classificálas segundo seu QI inato (Gould, 1991).

A maioria dos testes padronizados, visando à mensuração da inteligência, baseia-se em um conjunto de tarefas, verbais ou não-verbais, em que são exigidos tipos particulares de comportamentos, ou seja, de determinadas respostas diante de situações-problemas, que permitiriam verificar as habilidades e os tipos de relações que o indivíduo é capaz de estabelecer com o meio (Almeida, 1992; Anastasi, 1977; Leite, 1988; Ysseldyke, 1991). Assim, o resultado dos testes de inteligência, ainda que usualmente limitados aos seus escores, rótulos e classificações de inteligência é, na verdade, uma amostra comportamental, frente a um conjunto de tarefas, influenciável por situações ambientais diversas como: a história de vida, aprendizagens anteriores e habilidades acadêmicas, dentre elas a leitura.

Uma avaliação da leitura tanto quanto a da inteligência envolve uma amostragem diversificada de comportamentos. Independentemente da abordagem teórica sobre o comportamento de ler e de escrever, é consenso entre os diferentes teóricos que o indivíduo alfabetizado estabelece relações simbólicas mais amplas com o meio ambiente. Assim, é possível considerar que a habilidade de leitura pode afetar outras áreas, como, por exemplo, a das tarefas propostas para medir habilidades, conceitos, raciocínio, comumente empregadas em testes de inteligência de diferentes tipos. Parece que quanto maior o nível de aprendizagem da 'cultura' escolar, maior é a possibilidade de um bom desempenho nas tarefas diversas de um teste.

Historicamente construída há, em nossa cultura, uma tendência usual para se acreditar que os testes padronizados de inteligência são capazes de prever o fracasso ou o sucesso dos indivíduos nas habilidades acadêmicas gerais. Estudos realizados por Bima (1982) e por Oliveira (1986) mostram correlações entre pré-requisitos, nível intelectual e aprendizagem de leitura. Segundo Nunes, Buarque e Bryant (1992) diferenças entre o aprendizado de leitura nas crianças são esperadas, se considerarmos a sua relação com as habilidades intelectuais avaliadas em testes de inteligência através de escores de QI altos ou baixos. A relação entre inteligência e sucesso na alfabetização, porém, pode até envolver uma alta correlação, mas, como afirmam esses autores, "há crianças cujo progresso na alfabetização é muito melhor do que o esperado a partir da sua inteligência e, infelizmente, há aquelas cujo progresso na aprendizagem da leitura é muito pior do que seria esperado" (p.10). Outros autores questionam a questão da preditividade dos testes nos meios educacionais (Carraher \& Rego, 1984; Cohen \& Filipczak, 1971; Gatti, Patto, Costa, Kopit \& Almeida, 1981; Rodrigues, 1995).
Carraher e Rego (1984) realizaram um estudo com 130 alunos, de 4 a 13 anos, não- repetentes, de classes de alfabetização em três escolas do Recife, sendo uma escola pública de baixo nível sócio-econômico e as duas escolas particulares de médio e alto nível sócio- econômico, avaliadas em três ocasiões consecutivas (início, meio e fim) ao longo do ano letivo em que foram alfabetizadas. De modo geral, os resultados indicaram que o desempenho do aluno em conceber a palavra e seu referente como entidades independentes constitui um progresso na alfabetização: a aprendizagem de leitura e de escrita mostrou-se mais efetiva em crianças mais desenvolvidas no aspecto do realismo nominal, independentemente do tipo de escola freqüentada, do método de alfabetização e da inteligência verbal, avaliada pelo teste WISC. Ainda que os alunos da escola pública estivessem em um nível baixo quanto ao desenvolvimento cognitivo, observou-se um acentuado progresso quanto à aprendizagem, mesmo que essa aprendizagem fosse insuficiente para garantir-lhes uma aprovação escolar. Ou seja, embora as autoras não tivessem a relação entre QI e aprendizagem de leitura e escrita como objetivo central da pesquisa, é possível discutir esses dados concluindo que os resultados da avaliação cognitiva não puderam prever ou determinar os resultados de progresso em alfabetização.

Em um outro estudo para levantar supostas causas da reprovação na primeira série do primeiro grau, nas escolas da rede pública, com alunos repetentes e aprovados de diferentes realidades sociais e econômicas, Gatti e colaboradores (1981) mostraram que resultados baixos no teste de prontidão para a leitura e no teste de inteligência (WISC) não podem ser considerados causas ou explicações suficientes para a reprovação de alunos com história de fracasso escolar. Os autores consideraram o nível de desempenho em testes de prontidão para a leitura em dois grupos de alunos, aprovados e repetentes, em duas escolas: Escola A, carente e Escola B, não-carente sócio-economicamente.

Em ambas as escolas foram encontrados resultados do WISC com escores de QI abaixo da média normal da população - classificações de inteligência médio inferior, limítrofe ou deficiente - tanto nos alunos retidos como nos aprovados. O estudo concluiu pela não-relação entre baixa classificação em QI, prontidão para leitura e rendimento escolar nos alunos retidos ou aprovados, das duas escolas estudadas. Não houve, portanto, preditividade a partir dos resultados dos testes Metropolitano e WISC em relação à leitura e ao desempenho acadêmico (alfabetização desses alunos). Segundo os autores, os alunos retidos, em geral, apresentaram resultados mais baixos nas diferentes avaliações, 
mas tais resultados não explicavam a retenção, pois também houve resultados baixos entre os alunos aprovados.

Rodrigues (1995) investigou os chamados pré- requisitos, considerados imprescindíveis ou desejáveis para a aprendizagem de leitura e escrita e não observou relação direta entre os resultados dos instrumentos de avaliação e o aprendizado da leitura. Neste estudo, participaram 24 alunos com história de fracasso escolar, com idade entre 8 a 17 anos, oriundos de uma classe de escola especial e de duas classes de uma escola pública (uma classe especial e outra classe comum). Um teste de correlação entre os resultados nas avaliações do teste de Prontidão para Leitura e do teste WISC com o desempenho em leitura evidenciou que os pré-requisitos não seriam necessários para avaliar e/ou prever sucessos na aprendizagem de leitura. Essa autora concluiu que algumas habilidades, se adquiridas previamente, podem facilitar a aprendizagem de leitura, mas nem sempre em uma relação unidirecional, pois tais habilidades podem ser adquiridas concomitantemente com o ensino da leitura.

Cohen e Filipczak (1971) realizaram um estudo com jovens institucionalizados condenados pela justiça por comportamentos delinqüentes com pouco ou nenhum sucesso acadêmico, oferecendo-lhes um programa de reabilitação, voltado para a aprendizagem de comportamentos acadêmicos e sociais apropriados. Para a maioria dos estudantes, os resultados culturais e acadêmicos alcançados foram satisfatórios e acompanharam ganhos nos escores de QI. Dos 24 estudantes testados no início do programa pelo Army Revised Beta Examination (Teste de Inteligência) e re-testados ao final, 23 demonstraram um aumento de escore de QI e somente um permaneceu com o mesmo escore. A comparação das médias de escores de QI, no início e no término do programa em um intervalo de sete meses, mostrou um ganho médio de 12,5 pontos. Dezesseis dos 24 alunos tiveram escores de QI abaixo de 100 pontos na primeira medida do teste e apenas seis na segunda. Após um intervalo de tempo, ainda freqüentando o programa, esses mesmos alunos foram re-testados. Nesta terceira avaliação, 19 dos alunos foram avaliados novamente pelo teste e os dados confirmaram um aumento de escore, isto é, um ganho médio de QI de 16,2 pontos com relação à primeira avaliação. Estes dados sugerem, como apontam os próprios autores, que a melhora dos desempenhos nas diversas atividades acadêmicas acompanhou uma melhora de desempenho no teste de inteligência.

A literatura examinada conduz, fundamentalmente, à idéia de que parece não existir uma capacidade de previsão das dificuldades de aprendizagem em função de baixos escores de QI, resultados de testes de inteligência. Para investigar a relação entre as habilidades cognitivas e as acadêmicas com base nos pressupostos descritos, este estudo teve por objetivo verificar mudanças nos escores de QI e a sua relação com a leitura de palavras simples, considerando o desempenho de alunos do Ciclo Básico de alfabetização de uma escola pública, cursando salas de aulas regulares em que se desenvolviam, dentre vários outros, procedimentos tradicionais do ensino de leitura.

\section{Método}

\section{Participantes}

Participaram do estudo 56 alunos de uma escola pública regular, de ambos os sexos, com a idade entre 7 e 15 anos, que estavam cursando o Ciclo Básico de Alfabetização Inicial (CBI) ou de Continuação (CBC). Os alunos estavam distribuídos em três diferentes salas: 21 alunos na Sala 1 (CBI); 20 alunos na Sala 2 (CBC) e 15 alunos na Sala 3 (CBC). Quanto ao gênero, 36 alunos eram do sexo masculino $(64,3 \%)$ e 20 do sexo feminino $(35,7 \%)$. A maioria dos alunos concentrava-se nas faixas de idade entre: 7 anos e 8 anos e 11 meses (44,6\%) e 9 anos e 10 anos e 11 meses (37,5\%). A distribuição dos 56 alunos participantes em relação à idade encontra-se na Tabela 1.

Tabela 1

Distribuição dos Alunos por Sala de Aula, Conforme a Faixa Etária

Salas de aulas - ciclo básico de alfabetização

Faixa etária dos alunos

\begin{tabular}{lcccc}
\hline & Sala 1 & Sala 2 & Sala 3 & Total \\
& Inicial & Continuação & Continuação & 25 \\
7 anos a 8 anos e 11 meses & 18 & 03 & 04 & 21 \\
9 anos a 10 anos e 11 meses & 02 & 11 & 08 & 08 \\
11 anos a 12 anos e 11 meses & zero & 05 & 03 & 02 \\
13 anos a 14 anos e 11 meses & 01 & 01 & zero & 56 \\
\hline Total de alunos & 21 & 20 & 15 & \\
\hline
\end{tabular}


Não foi possível realizar a segunda avaliação de leitura em 6 alunos pois houve perda de sujeitos: 2 alunos da Sala 1, 1 da Sala 2 e 3 alunos da Sala 3; no entanto as duas avaliações do WISC foram realizadas para todos os alunos. Participaram, então, 50 alunos da avaliação de leitura e 56 alunos da avaliação do WISC.

\section{Instrumentos}

Para a avaliação do quociente de inteligência (QI) foi utilizado o WISC (Wechsler Intelligence Scale for Children Wechsler, 1949) com seu material específico, incluindo Manual de Instruções e protocolos de registro. Para a avaliação do repertório acadêmico - leitura - foi utilizado um Instrumento de Avaliação de Leitura e Escrita, desenvolvido por Fonseca e colaboradores (1995), com seu material específico e protocolo de registro. Dentre os materiais utilizados nessa avaliação, os estímulos usados foram figuras impressas - na cor branco e preto - e palavras, sílabas e letras grafadas em letra imprensa e letra cursiva. Ao todo, foram 42 vocábulos usados como estímulos na avaliação do repertório de leitura de palavras dissílabas e trissílabas, sem dificuldades, como por exemplo, as palavras: rio, rua, suco, tatu, boca, navio, rádio, tomate, cavalo, peteca, gaveta, macaco, entre outras.

Foram utilizados, também, jogos infantis, sem relação com as tarefas acadêmicas, para a interação entre experimentador e aluno ou para reforço social frente à participação destes nas atividades propostas em cada sessão. Para o registro das respostas, além dos protocolos redigidos, utilizou-se também uma câmara de vídeo, Panasonic M-1000, com tripé e um gravador Sony TCM71 para gravação do comportamento verbal.

\section{Procedimento}

Os alunos foram submetidos a uma avaliação de leitura e a uma avaliação do WISC, no primeiro semestre letivo (maio/junho), quando já estavam familiarizados com os respectivos professores. Seis meses depois (novembro e dezembro), após terem freqüentado regularmente a escola, os alunos foram submetidos a uma segunda avaliação de leitura e do teste WISC. A coleta e análise da avaliação do QI pelo WISC foi realizada pela primeira autora e a avaliação de leitura foi realizada pela segunda autora. Esse procedimento visou minimizar o viés da possibilidade de influência sobre o pesquisador que trabalhou com a informação dos dados de leitura, na ocasião da aplicação e avaliação do WISC.

As sessões de avaliação de leitura e as sessões de aplicação do WISC foram realizadas, individualmente com cada aluno, na própria escola dos participantes, em uma sala de aproximadamente $3 \times 2$ metros, reservada para a pesquisa, que continha uma mesa com cadeiras. A duração média de cada sessão foi de 30 minutos para as sessões de avaliação de leitura e de 50 minutos para as sessões de avaliação pelo WISC. Em cada sessão participaram o aluno, o experimentador e, pelo menos, um observador visando garantir a fidedignidade do registro. O cálculo de acordo era feito dividindo-se o total de concordância pelo total de respostas e multiplicando-se por 100 (Kazdin, 1982). Além disso, em ambas avaliações, da leitura e do WISC, uma amostra de $20 \%$ das sessões foi também gravada em áudio e vídeo.

A avaliação de leitura envolveu um conjunto de 18 tarefas consistentes com a noção de redes interligadas de relações comportamentais que caracterizam os repertórios de leitura e escrita (de Rose, de Souza, Rossito \& de Rose, 1989, 1992): a) seleção de estímulos (pareamento estímuloestímulo); b) tarefas de nomeação de figura e de texto (leitura), tarefas de cópia e ditado (manuscrito ou por composição) de letras, sílabas e palavras simples nas letras impressa e cursiva. Essas tarefas foram apresentadas aos alunos, uma a uma, em folhas de papel A4. O experimentador permanecia sentado ao lado direito do aluno e um ou dois observadores ficavam atrás do aluno, do lado esquerdo da sala, em uma posição adequada para que pudessem ver o manuseio do material pelo experimentador e as respostas do aluno sem estarem no seu campo de visão. Experimentador e observadores preenchiam um mesmo protocolo de registro de acordo com as respostas de cada aluno e posteriormente calculavam-se os acordos.

No presente estudo, foram utilizados somente os dados de leitura oral- nomeação de palavras - expressos em porcentagem de acerto em leitura de palavras simples inteiras (consoante-vogal). ${ }^{3}$

Os escores de QI foram obtidos mediante a aplicação do teste de inteligência WISC. Esse teste contempla duas áreas de avaliação e é composto por 12 sub-testes. A Área Verbal contempla os sub-testes: Informação, Compreensão, Aritmética, Semelhança, Vocabulário e Números. A Área de Execução contempla os sub-testes: Completar Figuras, Arranjo de Figuras, Armar Objetos, Código, Cubos e Labirinto.

A aplicação do WISC foi realizada pela mesma experimentadora, com formação acadêmica em psicologia e com experiência na aplicação do teste WISC. Cada aplicação do WISC foi realizada em local adequado, seguindo as regras

\footnotetext{
${ }^{3}$ Os resultados de todas as relações avaliadas no repertório de leitura foram apresentados por Fonseca (1997).
} 
e os critérios de aplicação e avaliação descritos em Wechsler (1949) e Glasser e Zimmerman (1977).

\section{Resultados}

Serão apresentados separadamente os resultados na avaliação de leitura, os resultados na avaliação do WISC e a relação entre essas variáveis.

\section{Avaliação do Repertório de Leitura}

A média inicial em leitura para todos os alunos, considerando as 42 palavras avaliadas, foi a de: 17,3\% na Sala 1, 75,4\% na Sala 2 e 36,3\% na Sala 3 e a média final em leitura (porcentagem das palavras lidas na segunda avaliação) para todos os alunos foi a de: $32,4 \%$ na Sala 1, $87,4 \%$ na Sala 2 e $62,7 \%$ na Sala 3.

$\mathrm{Na}$ Sala 1, na avaliação da leitura das 42 palavras realizada em 19 dos 21 alunos, 2 alunos leram todas as palavras na primeira avaliação e 6 alunos na segunda avaliação; 10 alunos não leram nem na primeira avaliação, nem na segunda, o que corresponde a um total de 52,6\% de toda a sala. $\mathrm{Na}$ Sala 2, na avaliação em leitura realizada em 19 dos 20 alunos, 8 alunos leram 100\% nas duas avaliações; 5 alunos leram quase todas as palavras na primeira avaliação (quatro alunos 93,3\% e 1 aluno 73,3\%) e todas as palavras na segunda avaliação. Dois alunos não leram na primeira avaliação e destes, um não leu nada e outro leu $60 \%$ das palavras, na segunda avaliação. Ressalte-se que somente um aluno desta sala não leu nada nas duas avaliações e 15 alunos leram todas as palavras na segunda avaliação em leitura. Finalmente, na Sala 3, na avaliação em leitura em 12, dos 15 alunos, 4 alunos leram todas as palavras nas duas avaliações; 5 alunos não leram nada na primeira avaliação sendo que desses, 4 leram entre 20 e $80 \%$ das palavras na segunda avaliação e 1 aluno não leu nada na segunda avaliação de leitura. Esses resultados podem ser vistos na Tabela 2 , ressaltando-se que houve perda de sujeitos e isso explica, quando se analisaram somente os dados de leitura, o fato de o número de alunos ser menor que na análise do WISC.

Tabela 2

Leitura de Palavras (N=42), Expresso em Porcentagem de Acerto e Escores de QI Total do WISC, nas Duas Avaliações, para Todos os Alunos

\begin{tabular}{|c|c|c|c|c|c|c|c|c|c|c|c|c|c|c|}
\hline & Sala & & & & \multicolumn{6}{|c|}{ Sala 2} & \multicolumn{4}{|c|}{ Sala 3} \\
\hline & \multicolumn{4}{|c|}{ Avaliações } & \multicolumn{6}{|c|}{ Avaliações } & \multicolumn{4}{|c|}{ Avaliações } \\
\hline & \multicolumn{2}{|c|}{ Leitura } & \multicolumn{2}{|c|}{ WISC } & & \multicolumn{2}{|c|}{ Leitura } & \multicolumn{2}{|c|}{ WISC } & & \multicolumn{2}{|c|}{ Leitura } & \multicolumn{2}{|c|}{ WISC } \\
\hline & $1^{\mathrm{a}}$ & $2^{a}$ & $1^{a}$ & $2^{a}$ & & $1^{a}$ & $2^{a}$ & $1^{a}$ & $2^{a}$ & & $1^{a}$ & $2^{a}$ & $1^{a}$ & $2^{a}$ \\
\hline Aluno & & & & & Aluno & & & & & Aluno & & & & \\
\hline A1 & 0 & 0 & 110 & 115 & A22 & 0 & 0 & 59 & 60 & A42 & 0 & 0 & 74 & 84 \\
\hline A2 & 0 & 0 & 90 & 93 & A23 & 0 & 60 & 86 & 98 & A43 & 0 & 20 & 85 & 85 \\
\hline A3 & 0 & 0 & 86 & 81 & A24 & 26,7 & 33,7 & 72 & 85 & A44 & 0 & 53,3 & 69 & 76 \\
\hline A4 & 0 & 0 & 85 & 78 & A25 & 40 & 100 & 58 & 62 & A45 & 0 & 66,7 & 57 & 66 \\
\hline A5 & 0 & 0 & 79 & 91 & A26 & 53,3 & 100 & 66 & 70 & A46 & 0 & 80 & 88 & 89 \\
\hline A6 & 0 & 0 & 79 & 88 & A27 & 66,7 & 66,7 & 58 & 70 & A47 & 11,1 & 12,5 & 54 & 64 \\
\hline A7 & 0 & 0 & 76 & 82 & A28 & 73,3 & 100 & 76 & 83 & A 48 & 12,5 & 46,7 & 60 & 69 \\
\hline A8 & 0 & 0 & 74 & 77 & A29 & 93,3 & 100 & 92 & 88 & A49 & 12,5 & 73,3 & 75 & 83 \\
\hline A9 & 0 & 0 & 70 & 81 & A30 & 93,3 & 100 & 87 & 87 & A50 & 100 & 100 & 93 & 91 \\
\hline A10 & 0 & 0 & 67 & 80 & A31 & 93,3 & 100 & 80 & 93 & A51 & 100 & 100 & 85 & 101 \\
\hline A11 & 0 & 16,7 & 68 & 72 & A32 & 93,3 & 100 & 64 & 68 & A52 & 100 & 100 & 66 & 65 \\
\hline A12 & 0 & 100 & 97 & 111 & A33 & 100 & 100 & 101 & 97 & A53 & 100 & 100 & 51 & 61 \\
\hline A13 & 0 & 100 & 89 & 96 & A34 & 100 & 100 & 90 & 94 & A54 & - & - & 71 & 75 \\
\hline A14 & 10 & 0 & 89 & 97 & A35 & 100 & 100 & 88 & 93 & A55 & - & - & 61 & 71 \\
\hline A15 & 12,5 & 0 & 62 & 62 & A36 & 100 & 100 & 85 & 83 & A56 & - & - & 60 & 60 \\
\hline A16 & 46,7 & 100 & 85 & 84 & A37 & 100 & 100 & 83 & 93 & & & & & \\
\hline A17 & 60 & 100 & 83 & 88 & A38 & 100 & 100 & 75 & 80 & & & & & \\
\hline A18 & 100 & 100 & 104 & 111 & A39 & 100 & 100 & 70 & 74 & & & & & \\
\hline A19 & 100 & 100 & 51 & 64 & A40 & 100 & 100 & 68 & 65 & & & & & \\
\hline A20 & - & - & 84 & 91 & A41 & - & -- & 70 & 67 & & & & & \\
\hline A21 & - & - & 57 & 67 & & & & & & & & & & \\
\hline
\end{tabular}




\section{Avaliação Psicométrica (Teste WISC)}

Os escores de QI. Total variaram, sendo predominante o aumento de escores de QI na segunda avaliação, para a maioria dos alunos $(82,1 \%$ dos alunos apresentaram uma variação no escore total de QI de 1 a até 16 pontos). Com relação ao decréscimo nos escores de QI, nas três salas, 10 alunos apresentaram decréscimo de valor na segunda medida de QI, variando de 1 a 7 pontos do escore total. A Tabela 2 também mostra os valores dos escores de QI (WISC) nas duas avaliações para os alunos nas três salas. A primeira avaliação do WISC resultou em escores de QI que variaram entre QI 51 e QI 110 na Sala 1; QI 58 e QI 101 na Sala 2 e QI 51 e QI 93 na Sala 3. Na segunda avaliação do WISC, os resultados dos escores mostraram uma variação de Q.I. 62 a QI 115 na Sala 1, QI 60 a QI 98 na Sala 2 e QI 60 a QI 101 na Sala 3. As médias de QI. Totais iniciais foram as de 80,2 (Sala 1); 76,4 (Sala 2); e 70 pontos (Sala 3), enquanto que, na segunda avaliação, as médias foram as de: 86,1 (Sala 1); 80,5 (Sala 2); e 76 pontos (Sala 3). Nas duas avaliações, os dados de QI de Execução foram, em média, maiores que os dados de QI Verbal para todos os alunos nas três salas. ${ }^{4}$

As classificações de Inteligência - resultantes do teste WISC- baseiam-se em intervalos de valores de escores de QI descritos em Wechsler (1949), e podem ser agrupados em três faixas de classificações: as consideradas acima da média da população (Superior e Muito Superior), as consideradas na média da população (sejam Médias Inferiores, Médias, e Médias Superiores) e, por fim, as consideradas abaixo da média da população (Limítrofe e Deficiente Mental). ${ }^{5}$

Nas duas avaliações, não houve, em nenhuma sala, a classificação de inteligência acima da média (Superior ou Muito Superior). As classificações de inteligência média na primeira avaliação, corresponderam na Sala 1 a 52,4\% dos alunos e, na segunda, esse número aumentou para $71,4 \%$. A Sala 2 apresentou quase a metade da sala (45\%) com inteligência média, na primeira avaliação, e esse percentual aumentou para $60 \%$ na segunda avaliação, e a Sala 3 apresentou a menor porcentagem de alunos com classificações de inteligência média $(26,7 \%)$ na primeira avaliação e essa porcentagem aumentou para $40 \%$ na

\footnotetext{
${ }^{4}$ Os resultados de todos os dados do WISC nas áreas verbal e de execução e nos 12 sub-testes foram apresentados por Bortolozzi (1997).

${ }^{5}$ Segundo Wechsler (1949), escores de QI Total entre 69 e valores abaixo correspondem à classificação de inteligência Débil (Deficiente Mental); escores de QI entre 70-79, classificação de inteligência Limitrofe; escores de QI entre 80-89, classificação de inteligência Médio Inferior; escores de QI entre 90-109, classificação Médio; escores de QI entre 110-119, classificação Médio Superior, escores de QI entre 120-129, classificação Superior, e escores de QI entre 130 e valores acima, classificação Muito Superior.
}

segunda avaliação. As classificações de inteligência abaixo da média na primeira avaliação, corresponderam na Sala 1 quase a metade dos alunos $(47,6 \%)$ e, na segunda, esse número se reduziu para $28,6 \%$ sendo os demais alunos classificados com inteligência média. A Sala 2 apresentou mais da metade da sala $(55 \%)$ com inteligência abaixo da média, na primeira avaliação, e diminuiu para $40 \%$ na segunda avaliação, e a Sala 3 apresentou a maior porcentagem de alunos com classificações de inteligência abaixo da média $(73,3 \%)$ na primeira avaliação e essa porcentagem diminuiu para $60 \%$ na segunda avaliação.

Temos, então, que das três salas, a Sala 3 foi a que mais apresentou classificações de inteligência abaixo da média nos dois momentos de avaliação; no entanto, em todas as salas, na segunda avaliação, ocorreu acréscimo de valores nos escores de QI para muitos alunos, o suficiente para alterar as classificações de inteligência determinadas pelos primeiros escores. Se pensarmos em todo o grupo de alunos participantes, no geral, observa-se que as classificações de inteligência foram alteradas a medida que houve acréscimo nos escores de QI. A Figura 1 mostra as classificações de inteligência média e abaixo da média, expressas em porcentagens das classificações, para todo o grupo de alunos, nos dois momentos das avaliações.

Nota-se que, de todos os alunos avaliados, a maioria deles obteve classificação de inteligência abaixo da média na primeira avaliação do WISC, e na segunda avaliação desse mesmo teste um contingente de alunos passou a

\section{Classificações de Inteligência}

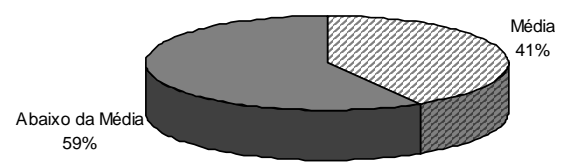

Primeira Avaliação do WISC

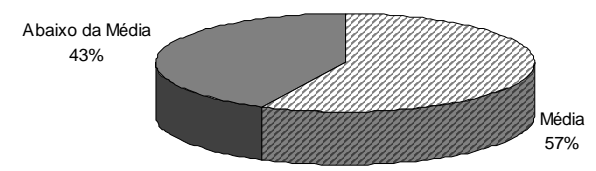

Segunda Avaliação do WISC

Figura 1. Freqüência das classificações da inteligência, para todo o grupo de alunos, nas duas avaliações do WISC. 
obter uma classificação de inteligência mediana (normal). Mesmo que muitos alunos tenham mantido suas classificações de inteligência abaixo da média ou na média, da primeira para a segunda avaliação do WISC, no geral, houve uma alteração na segunda medida do WISC, isto é, a maioria dos resultados obtidos, mediante a avaliação no teste, concentrou as classificações na média e não abaixo da média, como na primeira medida.

\section{Relação entre Quociente de Inteligência (WISC) e Aquisição de Leitura}

No geral, computando-se as três salas, a média de palavras lidas foi de $43 \%$ na primeira avaliação e de $60,8 \%$ na segunda e a média do escore de QI Total inicial foi de 75,5 pontos na primeira avaliação e de 80,7 pontos na segunda. Ou seja, no geral, houve aumento nos escores de QI assim como aumento na porcentagem de acerto na leitura das palavras avaliadas.

Tanto alunos com classificações de inteligência média quanto os relacionados como abaixo da média, apresentaram leitura de palavras na primeira e na segunda avaliação. Dos 23 alunos com classificação de inteligência média, 15 deles $(65,2 \%)$ leram todas as palavras na segunda avaliação (sendo que desses, 8 já haviam lido todas as palavras na primeira avaliação). Dos 27 alunos com classificação de inteligência abaixo da média, 10 deles (37\%) leram todas as palavras na segunda avaliação, sendo que desses, 6 já haviam lido todas as palavras na primeira avaliação. Embora tenha havido mais alunos que leram todas as palavras nas duas avaliações, classificados com inteligência média, não é possível afirmar que essas classificações tenham relação com o desempenho em leitura, pois também houve alunos, considerados abaixo da média em inteligência, que leram todas as palavras na primeira e na segunda avaliação.

Em geral, houve aumento na leitura das palavras e aumento nos escores de QI do WISC nas avaliações dos alunos; no entanto, esses desempenhos não parecem associados entre si. Uma análise estatística investigou a possibilidade da correlação entre leitura de palavras e os resultados do WISC (escores de QI Total, de Execução e Verbal) para todos os participantes e concluiu pela inexistência de correlações entre essas variáveis, como pode ser visto na Tabela 3.

A correlação entre os resultados no WISC foi altamente significativa (parte superior da Tabela 3), entre os escores de QI Total, QI de Execução e QI Verbal, como seria de se esperar pois esta correlação indica que o resultado do WISC Total é um índice composto a partir das duas áreas (verbal e execução), quando os escores são cruzados no mesmo momento, e indica ainda que há uma estabilidade entre os escores do WISC (Verbal, Execução e Total) quando cruzados em momentos distintos.

No entanto, mesmo assim, as correlações entre os resultados de leitura e os escores do WISC foram praticamente inexistentes. Se houvesse um relacionamento entre essas variáveis, a correlação entre a leitura e o WISC Total - ou qualquer correlação entre a leitura e uma subárea do WISC - teria que ser significativa nos dois momentos da pesquisa (parte inferior da Tabela 3). Todas essas correlações foram calculadas e analisadas para cada uma das três salas de aulas, isoladamente. O grupo total de participantes também foi dividido por diferentes faixas etárias, repetindo-se o cálculo do mesmo conjunto de

Tabela 3

Correlações Cruzadas no Mesmo Momento e em Momentos Distintos entre as Variáveis WISC (Escores de QI) e Leitura

\begin{tabular}{lccc}
\hline \multicolumn{1}{c}{ Variáveis } & $1^{\circ}$ Momento & $2^{\circ}$ Momento & $1^{\circ}$ para o $2^{\circ}$ Momento \\
\hline QI total x QI verbal & $0,9 *^{*}$ & $0,90 *$ & $0,82 *$ \\
QI total x QI execução & $0,91^{*}$ & $0,89 *$ & $0,82 *$ \\
QI verbal x QI execução & $0,64 *$ & $0,61 *$ & $0,61 *$ \\
& & & 0,01 \\
\% leitura x QI total & 0,05 & 0,04 & 0,05 \\
\% leitura x QI verbal & 0,06 & 0,02 & $-0,01$ \\
\% leitura x QI execução & 0,05 & 0,07 & \\
\hline
\end{tabular}

Nota. As correlações (momento produto de Pearson) foram obtidas com a análise de uma amostra de 56 alunos e os dados faltantes foram substituídos pelas respectivas médias; $p<0,01$. 
correlações para os dois tipos de escores empregados e os resultados apenas confirmaram o que já fora observado e descrito para todo o grupo de alunos ${ }^{6}$.

Para melhor analisarmos a relação entre o desempenho em leitura e a variação dos escores no WISC, uma vez que o repertório inicial em leitura foi diferenciado nas três salas, os alunos foram agrupados em três sub-grupos, tendo em comum os seus desempenhos na avaliação de leitura: alunos que não aprenderam a ler (Grupo A), os que estavam adquirindo a leitura (Grupo B) e os que já liam desde a primeira avaliação (Grupo C).

De todo o grupo de alunos, 11 alunos constituíram o Grupo A, pois não apresentaram leitura na primeira nem na segunda avaliação. Quatorze alunos constituíram o Grupo $\mathrm{C}$, pois apresentaram a leitura de todas as palavras nas duas avaliações. Um pequeno grupo de 6 alunos constituiu o Grupo B, pois esses alunos apresentaram uma mudança mais consistente no desempenho em leitura, com nenhuma leitura na primeira avaliação e leitura das palavras igual ou maior a $50 \%$ na segunda avaliação. Desse grupo, apenas 2 alunos que não leram nada na primeira avaliação leram todas as palavras na segunda avaliação, enquanto que os demais alunos leram entre $50 \%$ e $80 \%$ das palavras $(53,3 \%, 60 \%$, $66,7 \%$ e $80 \%$ ). A Figura 2 mostra a variação do QI Total medido pelo WISC nesses alunos, distribuídos nos referidos

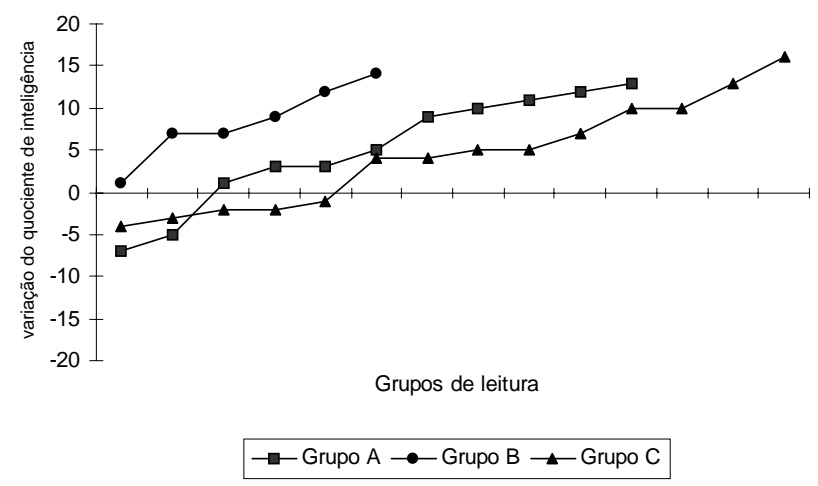

Figura 2. Variação do escore de QI dos alunos distribuídos em grupos conforme o desempenho nas avaliações de leitura.

grupos já descritos, de acordo com seu desempenho na leitura da primeira para a segunda avaliação.

A variação nos escores de QI. Total foi negativa (decréscimo de valor) em mais alunos do Grupo C (5 de 14 alunos), grupo este que não apresentou mudança na

\footnotetext{
${ }^{6} \mathrm{O}$ mesmo cálculo foi realizado com um valor predito (escores de mudança residualizados obtidos após a retirada da influência dos valores iniciais) e os resultados da análise mantiveram-se os mesmos.
}

leitura das palavras, uma vez que todos já liam desde a primeira avaliação. No Grupo A, apenas 2, dos 11 alunos, apresentaram decréscimo de valor nos escores de QI. No Grupo B nenhum aluno, dos 6 alunos do grupo, apresentou decréscimo de valor nos escores de QI, e sim uma variação positiva de até 12 pontos. Em geral, houve um aumento nos escores de QI para todos os alunos, nos três sub-grupos, quer para os que não aprenderam a ler durante o ano (Grupo A), quer para os que já liam desde o início do ano (Grupo C), quer para os que apresentaram uma aquisição de leitura (Grupo B).

\section{Discussão}

Em geral, a leitura das palavras avaliadas aumentou para todos os alunos, nas três salas. O menor índice de leitura, em média, foi o da Sala 1 (Ciclo Básico Inicial) nas duas avaliações, o que pode estar relacionado ao fato de os alunos desta sala estarem ingressando na escola e estarem tomando contato com os procedimentos sistemáticos de ensino pela primeira vez ou, ainda, pela maioria dos alunos desta sala encontrarem-se na menor faixa etária (7 a 8 anos e 11 meses) em relação aos alunos das outras duas salas.

Todos os alunos ficaram expostos diariamente, por pelo menos 6 meses, a métodos de ensino de leitura e de habilidades acadêmicas. Na segunda avaliação da leitura das palavras simples (dissílabas e trissílabas), 5 alunos obtiveram índices de leitura menor que $50 \%$ e 14 alunos não foram capazes de ler nenhuma das palavras avaliadas. Considerando que o processo de alfabetização é mais complexo que a leitura de palavras simples, incluindo aí, por exemplo, a construção de frases e a interpretação de textos, os resultados deste estudo podem indicar que alguns índices de leitura de palavras simples foram baixos, para alguns alunos, na segunda avaliação.

A média de QI Total medido pelo WISC, em geral, nas três salas, aumentou da primeira para a segunda avaliação. A Sala 1 apresentou a maior média de QI nas duas avaliações e a Sala 3 a menor média também nas duas avaliações, mas nas três salas houve, em média, aumento nos escores de QI. A partir desse aumento de QI na segunda avaliação, é possível sugerir que o resultado do teste de inteligência é um processo influenciado pela interação dos indivíduos com o meio e com múltiplas variáveis, compartilhando-se, então, da idéia dos autores Almeida (1992), Carraher (1989) e Hickel (1992).

Apesar dos aumentos tanto no acerto em leitura das palavras quanto nos escores do WISC, não houve correlação entre essas variáveis como preconizavam autores como Bima (1982) e Oliveira (1986), mas sim, algumas evidências 
contrárias. Alunos que já liam na primeira avaliação e outros que liam pouco ou não liam nada, obtiveram acréscimo ou decréscimo nos seus escores de QI independentemente de seus desempenhos na segunda leitura. Uma análise mais restrita, sugerida pela hipótese de que talvez o processo de aprendizagem de leitura pudesse, de alguma maneira, estar influenciando os ganhos nos escores de QI, relacionou a leitura e os escores do WISC apenas daqueles alunos que mostraram, de alguma forma, estarem em processo de aquisição de leitura simples, descartando os alunos que já liam e os que não aprenderam a ler. Neste caso, houve aumento dos escores de QI para os 6 alunos desse grupo, mas tais dados não podem ser relacionados entre si, nem tampouco garantir uma análise mais conclusiva. Isto porque, neste caso, os dados são escassos e a relação observada entre as variáveis QI e Leitura pode ter ocorrido de maneira esporádica; além disso, para estes 6 alunos os ganhos na leitura das palavras não foram efetivos (somente 2 alunos não leram nada na primeira avaliação e passaram a ler todas as palavras, na segunda). Daí, sugerem-se novas investigações neste sentido.

Uma concepção tradicional sobre inteligência tem preconizado que, de acordo com as classificações de inteligência determinadas pelos resultados do WISC, os alunos que se encontram na faixa média, estariam aptos a se alfabetizarem e os alunos com classificações abaixo da média necessitariam de recursos especiais de ensino. As classificações de inteligência a partir do desempenho no WISC, para todo o grupo de alunos, foram em ambas as avaliações na média e/ou abaixo da média tendo sido observada, no geral, uma mudança de classificação de uma avaliação para a outra $\mathrm{e}$, ainda, não relacionada aos ganhos em leitura. A relação entre a classificação de inteligência média para possíveis aprendizes e abaixo da média para possíveis não-aprendizes na aprendizagem de leitura não foi verdadeira, pois em ambos os casos o desempenho na segunda avaliação em leitura não teve relação com a classificação da inteligência inicial (primeira medida no teste WISC). Isto é, alunos com inteligência abaixo da média foram tão capazes de ler quanto os de inteligência média ou normal, dados esses, semelhantes aos do estudo de Carraher e Rego (1984). Tais dados também corroboram os estudos de Gatti e colaboradores (1981) e de Rodrigues (1995) em que os resultados em testes de inteligência não garantiram, nem explicaram o sucesso ou fracasso dos alunos nas atividades acadêmicas.

Neste sentido, muitos alunos deste estudo, em decorrência do resultado em um teste de inteligência, foram diagnosticados na primeira avaliação como dotados de uma inteligência abaixo da média (Limítrofes ou Deficientes Mentais) e em uma nova avaliação do mesmo teste foram considerados normais pois aumentaram seus escores de Q.I. Como prever, então, já na primeira avaliação pelo teste de inteligência o futuro escolar desses alunos se ao final do ano, na segunda avaliação, muitos alunos apresentaram diferentes - e mais altos - escores e classificações de inteligência? Este questionamento vai ao encontro da preocupação de autores como Almeida (1992), Carvalho (1993), Fonseca (1987), Kassar (1995), Machado (1996), Maia (1997) e Salazar (1997) em relação aos laudos psicológicos que, baseados em classificações da inteligência, têm em geral determinado rótulos, estigmas e carreiras de fracassos aos alunos sob uma medida de Q.I. considerada imutável.

O estudo enseja futuras investigações. Os escores de QI Total obtidos no teste de inteligência (WISC) não foram suficientes para prever o sucesso ou o fracasso dos alunos quanto aos seus desempenhos na habilidade de leitura de palavras simples nem se apresentaram correlacionados. A discussão decorrente da relação estudada, isto é, entre um teste de inteligência e o desempenho na habilidade de leitura, extrapola os 'muros' da escola e instiga a necessidade de outras investigações e de uma reflexão cuidadosa sobre o uso de testes de inteligência em avaliações psicológicas como instrumentos capazes de prever o futuro no desempenho escolar dos alunos avaliados, elucidações estas que seriam imprescindíveis ao trabalho dos psicólogos, educadores, profissionais e pesquisadores, sobretudo na área da Educação Especial.

\section{Referências}

Almeida, L. S. (1992). Inteligência e aprendizagem: Dos seus relacionamentos à sua promoção. Psicologia: Teoria e Pesquisa, 8, 277- 292.

Anastasi, A. (1977). Testes psicológicos. São Paulo: EPU.

Bima, H. J. (1982). Validade do conceito de prontidão para a leitura e escrita. Dissertação de Mestrado não-publicada, Curso de Pós- Graduação, Universidade Federal de Santa Maria. Santa Maria, RS.

Bortolozzi, A.C.P. (1997). Aprendizagem de leitura e desempenho no WISC em crianças com história de fracasso escolar. Dissertação de Mestrado nãopublicada, Curso de Pós-Graduação em Educação Especial, Universidade Federal de São Carlos. São Carlos, SP.

Carraher, T. N. (1989). Sociedade e inteligência. São Paulo: Cortez.

Carraher, T. N. \& Rego, L. L. B. (1984). Desenvolvimento cognitivo e alfabetização. Revista Brasileira de Estudos Pedagógicos, 65, 38-55.

Carvalho, R. E. (1993). Avaliação e atendimento em educação especial. Em T. R. Dias, F. E. Denari \& O. M. Kubo (Orgs.), Temas em educação especial (Vol.2, pp. 65-74). São Carlos, SP: UFSCar.

Cohen, H. \& Filipczak, J. (1971). A new learning environment. Boston: Authors Cooperative.

de Rose, J. C. C., de Souza, D. G., Rossito, A. L. \& de Rose, T. M. S. (1989). Aquisição de leitura após história de fracasso escolar. Psicologia: Teoria e Pesquisa, 5, 325-346.

de Rose, J. C. C., de Souza, D. G., Rossito, A. L. \& de Rose, T. M. S. (1992). Stimulus equivalence and generalization in reading after matching to sample by exclusion. Em S.C. Hayes \& L. J. Hayes (Orgs.), Understanding verbal relations (pp. 69-82). Reno, Nevada: Context. 
Fonseca, M. L. (1997). Diagnóstico de repertórios inicias de leitura e escrita: Uma análise baseada na concepção de relações de equivalência. Dissertação de Mestrado não-publicada, Curso de Pós-Graduação em Educação Especial, Universidade Federal de São Carlos. São Carlos, SP.

Fonseca, M. L., Fonseca, M. G., Bortolozzi, A. C., Bernardes, A.C., Carvalho, A. E. N., Gallo, E., Colenci, A. T., Nono, M. A., Arioli, V. C., de Souza, D. G., de Rose, J. C. \& Hanna, E. S. (1995). Avaliação de um instrumento para caracterização dos repertórios de leitura e escrita de alunos do Ciclo Básico [Resumos]. Em Sociedade Brasileira de Psicologia (Org.), Anais, XXV Reunião Anual de Psicologia (p. 428). Ribeirão Preto, SP: SBP.

Fonseca, V. (1987). Educação especial. Porto Alegre: Artes Médicas.

Gatti, B. A., Patto, M. H. S., Costa, M. L., Kopit, M. \& Almeida, R. M. A. (1981). Reprovação na $1^{\text {a }}$ série da $1^{\circ}$ grau: Um estudo de caso. Cadernos de Pesquisa, 38, 3-13.

Glasser, A. \& Zimmerman, I. (1977). Interpretación clínica de la escala de inteligência de Wechsler para niños (WISC). Madrid: TEA.

Gould, S. J. (1991). A falsa medida do homem. São Paulo: Martins Fontes.

Hickel, N. (1992). A inteligência é um processo e não um dom: Fica-se mais inteligente porque se aprende. Em E. P. Grossi (Org.), Paixão de aprender. Petrópolis, RJ: Vozes.

Kazdin, A. E. (1982). Single-case research designs. New York: Oxford University.

Kassar, M. C. M. (1995). Ciência e senso comum no cotidiano das classes especiais: Série Educação Especial. Campinas, SP: Papirus.

Leite, S. A. S. (1988). O fracasso escolar no ensino de primeiro grau. Revista Brasileira de Estudos Pedagógicos, 69, 510-540.

Machado, A. M. (1996). Reinventando a avaliação psicológica. Tese de Doutorado não-publicada, Curso de Pós Graduação em Psicologia Escolar, Universidade de São Paulo. São Paulo, SP.
Maia, A.C.B. (1997). Avaliação psicológica: Uma reflexão sobre laudos. Revista Mimesis, 18(1), 119-126.

Nunes, T., Buarque, L. \& Bryant, P. (1992). Dificuldades na aprendizagem da leitura: Teoria e prática (Vol.47). São Paulo: Cortez/Autores Associados.

Oliveira, Q. L. (1986). Estudo psicométrico de quatro instrumentos de avaliação da prontidão para a leitura e escrita. Tese de Doutorado não-publicada, Curso de Pós Graduação em Psicologia Escolar, Universidade de São Paulo. São Paulo, SP.

Patto, M. H. S. (1992). A família pobre e a escola pública: Anotações sobre um desencontro. Psicologia USP, 3(1-2), 107-121.

Rodrigues, O. M. P. R. (1995). Desempenho de entrada e aprendizagem de leitura: Em busca de relação. Tese de Doutorado não-publicada, Curso de Pós Graduação em Psicologia Experimental, Universidade de São Paulo. São Paulo, SP.

Salazar, R. M. (1997). O laudo psicológico e a classe especial: Uma análise de laudos psicológicos utilizados no encaminhamento de crianças às classes especiais. Dissertação de Mestrado não-publicada, Curso de Pós-Graduação em Psicologia da Educação, Pontifícia Universidade Católica de São Paulo. São Paulo, SP.

Wechsler, D. (1949). Wechsler Intelligence Scale for Children (WISC). New York, NY: Psychological.

Ysseldyke, S. (1991). Avaliação em educação especial e corretiva. São Paulo: Manole.

Recebido: 24/01/2001

Revisado: 12/07/2001

Aceito: 22/10/2001

Sobre as autoras

Ana Cláudia Bortolozzi Maia é Psicóloga, Mestre em Educação Especial pela Universidade Federal de São Carlos (UFSCar); Doutoranda em Educação pela UNESP, Marília/SP. Atualmente é Docente do Curso de Graduação em Psicologia lotada junto ao Departamento de Psicologia da UNESP, Bauru/SP.

Mônica Lucia Fonseca é Pedagoga e Psicóloga, Mestre em Educação Especial pela Universidade Federal de São Carlos (UFSCar), São Carlos/SP; Auxiliar de Pesquisa na Unidade de Iniciação à Leitura para escolares de risco na UFSCAR, São Carlos/SP. 